\title{
Role of insulin-like growth factor 1 , sex and corticosteroid hormones in male major depressive disorder
}

\author{
Hiroshi Arinami, Yutaro Suzuki, Misuzu Tajiri, Nobuto Tsuneyama and Toshiyuki Someya
}

\begin{abstract}
Background: Hormones of the hypothalamic-pituitary-gonadal (HPG), hypothalamic-pituitary-adrenal (HPA), and hypothalamic-pituitary-somatotropic (HPS) axes are potentially involved in major depressive disorder (MDD), but these hormones have not been simultaneously investigated in male patients with MDD. We investigated the association between male MDD symptoms and estradiol, testosterone, cortisol, dehydroepiandrosterone sulfate (DHEAS), and insulin-like growth factor 1 (IGF1).

Methods: Serum estradiol, testosterone, cortisol, DHEAS, and IGF1 levels were measured in 54 male patients with MDD and 37 male controls and were compared with clinical factors. We investigated the associations between hormone levels and Hamilton Depression Rating Scale (HAM-D) scores. The correlations among hormones were also investigated.
\end{abstract}

Results: Patients had significantly lower estradiol levels than controls $(22.4 \pm 8.4 \mathrm{pg} / \mathrm{mL}$ vs. $26.1 \pm 8.5 \mathrm{pg} / \mathrm{mL}, P=$ 0.040). Serum estradiol levels were negatively correlated with HAM-D scores $(P=0.000094)$ and positively correlated with Global Assessment of Functioning scores $(P=0.000299)$. IGF1 levels and the cortisol:DHEAS ratio were higher in patients than in controls (IGF1: $171.5 \pm 61.8 \mathrm{ng} / \mathrm{mL}$ vs. $144.1 \pm 39.2 \mathrm{ng} / \mathrm{mL}, P=0.011$; cortisol:DHEAS ratio: $0.07 \pm$ 0.05 vs. $0.04 \pm 0.02, P=0.001)$. DHEAS levels were lower in patients than in controls $(227.9 \pm 108.4 \mu \mathrm{g} / \mathrm{dL}$ vs. $307.4 \pm$ $131.2 \mu \mathrm{g} / \mathrm{dL}, P=0.002$ ). IGF1, cortisol:DHEAS ratio, and DHEAS were not significantly correlated with HAM-D scores. Cortisol and testosterone levels were not significantly different between patients and controls. Serum estradiol levels were positively correlated with DHEAS levels $(P=0.00062)$ in patients, but were not significantly correlated with DHEAS levels in controls.

Conclusion: Estradiol may affect the pathogenesis and severity of patients with MDD in men, and other hormones, such as those in the HPA and HPS axes, may also be involved in male MDD. Additionally, a correlation between estradiol and DHEAS may affect the pathology of MDD in men.

Keywords: Cortisol, DHEAS, Estradiol, IGF1, Testosterone

\footnotetext{
* Correspondence: yutaro@med.niigata-u.ac.jp

Department of Psychiatry, Niigata University Graduate School of Medical and

Dental Sciences, 1-757 Asahimachi-dori, Chuo-ku, Niigata 951-8510, Japan
}

(C) The Author(s). 2021 Open Access This article is licensed under a Creative Commons Attribution 4.0 International License, which permits use, sharing, adaptation, distribution and reproduction in any medium or format, as long as you give appropriate credit to the original author(s) and the source, provide a link to the Creative Commons licence, and indicate if changes were made. The images or other third party material in this article are included in the article's Creative Commons licence, unless indicated otherwise in a credit line to the material. If material is not included in the article's Creative Commons licence and your intended use is not permitted by statutory regulation or exceeds the permitted use, you will need to obtain permission directly from the copyright holder. To view a copy of this licence, visit http://creativecommons.org/licenses/by/4.0/ The Creative Commons Public Domain Dedication waiver (http://creativecommons.org/publicdomain/zero/1.0/) applies to the data made available in this article, unless otherwise stated in a credit line to the data. 


\section{Introduction}

The incidence of major depressive disorder (MDD) differs by sex [1]; therefore, the pathogenesis of MDD is likely to be affected by sex hormones of the hypothalamic-pituitary-gonadal (HPG) axis. The association between testosterone and MDD in men has been studied $[1,2]$, and testosterone receptors have been found to be present in numerous brain regions associated with mood, such as the hippocampus and amygdala [1]. In recent years, the association between estradiol and men has also been reported. In studies of men with hypogonadism or gender identity disorder (male to female), estrogen treatment has reduced stress responses and symptoms of depression [3-6]. However, few studies have investigated the relationship between symptom severity in male patients with MDD and estradiol, including testosterone.

The hypothalamus-pituitary-adrenal (HPA) axis has been widely studied with respect to the pathogenesis of MDD. In patients with MDD, increased cortisol and decreased dehydroepiandrosterone sulfate (DHEAS) have been reported [7-11]. Through anti-glucocorticoid effects, DHEAS has protective effects against the neurotoxicity of cortisol [11]; therefore, changes in the cortisol:DHEAS ratio may represent a sensitive indicator of HPA function [12]. More recently, the association between the HPA and HPG axes has been examined [1315], but few studies have simultaneously considered the HPA and HPG axes in male patients with MDD.

Insulin-like growth factor 1 (IGF1) is produced in the hypothalamic-pituitary-somatotropic (HPS) system and is suggested to be involved in the pathogenesis of MDD through its neuroprotective, neurogenic, and antiinflammatory effects [16]. Although associations between the HPS and HPG axes have been reported [17, 18], these relationships in male MDD are not well understood.

In addition to sex hormones, the HPA and HPS axes vary between men and women $[13,19,20]$, but the relationship between MDD and these hormones in men is not well understood because most previous studies have involved women. Moreover, the combined role of each hormone and the relationships among hormones in male MDD are unclear because no studies have examined the HPA, HPS, or HPG axes simultaneously. The aim of this study, therefore, was to clarify the role of hormones in male MDD and the relationships between these hormones.

\section{Methods}

\section{Participants}

We studied 54 male patients with MDD attending or hospitalized at the Niigata University Medical \& Dental Hospital and 37 healthy male volunteers. All participants were aged $18-65$ years. Patients were diagnosed with MDD according to the criteria specified in the Diagnostic and Statistical Manual of Mental Disorders, Fifth Edition and were not combined with other psychiatric diagnoses, such as drug or alcohol abuse, bipolar disorder, delusional disorder, anxiety disorder, and dementia. Exclusion criteria included a history of serious physical diseases (e.g., malignancy; infection; autoimmune disease; and heart, lung, liver, gastrointestinal, kidney, neurological, and endocrine disease), and a history of steroid hormone use. The patients received individualized treatment from clinicians.

This study was approved by the Genetics Ethics Committee of Niigata University Graduate School of Medical and Dental Sciences (approval number G - 0758) and followed the ethical principles of the Declaration of Helsinki.

All participants were informed of the study's aims and procedures and provided written informed consent before participating in the study. Informed consent was obtained from parents and/or legal guardian of patients with MDD if the patient's capacity to provide consent was compromised.

\section{Assessment of symptoms in patients with MDD}

The mental status of patients was assessed by a psychiatrist who was not the patient's attending physician. Symptoms of depression were assessed using the Hamilton Depression Rating Scale (HAM-D). Social, occupational, and psychological functioning were assessed using the Global Assessment of Functioning (GAF) scale [21]. Scores of the GAF scale range from 1 to 100, with scores closer to 100 indicating better function.

\section{Blood samples and physical measurements}

All blood samples were collected in the morning after at least $8 \mathrm{~h}$ of fasting. Smoking, exercise, and activities that could lead to excessive stress, such as work, were prohibited on the morning before blood samples were collected. Serum samples were centrifuged at $4{ }^{\circ} \mathrm{C}$ and stored at $-80^{\circ} \mathrm{C}$. Sera were analyzed using standard methods (SRL Inc., Tokyo, Japan). The body mass index (BMI) of participants was measured when blood samples were collected.

\section{Data analysis and statistics}

Unpaired $t$-tests and chi-squared tests were used to compare the patient group with the control group. Correlations between hormone levels, HAM-D, and GAF were analyzed using the Pearson correlation coefficient. To investigate the factors affecting HAM-D, stepwise multiple regression analysis was performed using serum estradiol level, age, BMI, type of antidepressant, total imipramine equivalence, and duration of illness as 
independent variables. To investigate the correlation between hormones, multiple regression analysis was performed using estradiol and IGF1 as dependent variables, age, BMI, and each hormone level as independent variables. $P$ values of less than 0.05 were considered statistically significant. All analyses were performed using IBM SPSS 25 (IBM Japan, Tokyo, Japan).

\section{Results}

The clinical characteristics of the included patients are shown in Table 1. As shown in Table 2, in terms of age, BMI, smoking history, and glycated hemoglobin (HbA1c), there were no significant differences between the two groups. Serum estradiol levels and serum DHEA $S$ levels were lower in the MDD group than in the control group (Table 2). The cortisol:DHEAS ratio and serum IGF1 levels in the MDD group were higher than those in the control group (Table 2). No significant differences in serum cortisol levels and serum testosterone levels were found between the MDD group and control group (Table 2).

On the basis of Pearson correlation analysis, serum estradiol levels were negatively correlated with HAM-D scores $(\mathrm{R}=-0.506, P<0.001) \quad$ (Fig. 1a) and positively

Table 1 Clinical characteristics of patients with MDD

\begin{tabular}{|c|c|c|}
\hline \multicolumn{3}{|l|}{ Variables } \\
\hline$\overline{\mathrm{Age}^{\mathrm{a}}}$ & year & $42.4 \pm 14.7$ \\
\hline Body mass index ${ }^{a}$ & $\mathrm{~kg} / \mathrm{m}^{2}$ & $24.2 \pm 3.1$ \\
\hline Smoker / non smoker & $n$ & $13 / 41$ \\
\hline HAM-D ${ }^{a}$ & & $19.3 \pm 7.0$ \\
\hline $\mathrm{GAF}^{\mathrm{a}}$ & & $32.4 \pm 7.6$ \\
\hline Duration of illness ${ }^{a}$ & year & $6.2 \pm 7.9$ \\
\hline No. depressive episodes ${ }^{a}$ & & $1.7 \pm 1.1$ \\
\hline Antidepressant use & n (\%) & $39(72.2)$ \\
\hline TCA & n (\%) & $1(1.8)$ \\
\hline SSRI & n (\%) & $27(50.0)$ \\
\hline SNRI & n (\%) & $7(13.0)$ \\
\hline NaSSA & n (\%) & $4(7.4)$ \\
\hline Imipramine equivalence ${ }^{a}$ & mg/day & $110.7 \pm 95.4$ \\
\hline Benzodiazepine use & n (\%) & $17(31.5)$ \\
\hline \multicolumn{3}{|c|}{ Severity/course specifier at first medical examinationenzodiazepine use } \\
\hline Mild & n (\%) & $14(25.9)$ \\
\hline Moderate & n (\%) & $29(53.7)$ \\
\hline Severe & n (\%) & $5(9.2)$ \\
\hline With psychotic features & n (\%) & $3(5.6)$ \\
\hline In partial remission & n (\%) & $3(5.6)$ \\
\hline
\end{tabular}

${ }^{a}$ Values are presented as mean \pm standard deviation

Abbreviations: HAM-D Hamilton Rating Scale for Depression, TCA Tricyclic antidepressants, SSRI Selective serotonin reuptake inhibitors, SNRI Serotoninnorepinephrine reuptake inhibitors, NaSSA Noradrenergic and specific serotonergic sntidepressant
Table 2 Comparative profile of male patients with MDD and control participants

\begin{tabular}{llll}
\hline Variables & MDD $^{\mathbf{1}}$ & Control & $P$ value \\
\hline Number & 54 & 37 & - \\
Age $(\text { year) })^{\mathrm{a}}$ & $42.4 \pm 14.7$ & $39.4 \pm 7.0$ & $P=0.187 \dagger$ \\
Body mass index $\left(\mathrm{kg} / \mathrm{m}^{2}\right)^{\mathrm{a}}$ & $24.2 \pm 3.1$ & $24.0 \pm 3.5$ & $P=0.661 \dagger$ \\
Smoker/non smoker & $13 / 41$ & $5 / 32$ & $P=0.214 \ddagger$ \\
HbA1c $(\%)^{\mathrm{a} 4}$ & $5.4 \pm 0.5$ & $5.4 \pm 0.8$ & $P=0.970 \dagger$ \\
Cortisol $(\mu \mathrm{g} / \mathrm{dll})^{\mathrm{a}}$ & $12.1 \pm 4.8$ & $11.1 \pm 3.0$ & $P=0.191 \dagger$ \\
DHEAS $(\mu \mathrm{g} / \mathrm{dl})^{\mathrm{a} 2}$ & $227.9 \pm 108.4$ & $307.4 \pm 131.2$ & $P=0.002 \dagger$ \\
Cortisol / DHEAS ratio & $0.07 \pm 0.05$ & $0.04 \pm 0.02$ & $P=0.001 \dagger$ \\
IGF1 $(\mathrm{ng} / \mathrm{ml})^{\mathrm{a} 3}$ & $171.5 \pm 61.8$ & $144.1 \pm 39.2$ & $P=0.011 \dagger$ \\
Testosterone $(\mathrm{ng} / \mathrm{ml})^{\mathrm{a}}$ & $5.0 \pm 1.6$ & $4.9 \pm 1.6$ & $P=0.709 \dagger$ \\
Estradiol $(\mathrm{pg} / \mathrm{ml})^{\mathrm{a}}$ & $22.4 \pm 8.4$ & $26.1 \pm 8.5$ & $P=0.040 \dagger$
\end{tabular}

${ }^{a}$ Data are expressed as the mean \pm standard deviation. +Unpaired t-test. $\neq$ Chisquared tests. Abbreviations: ${ }^{1} M D D$ Major depressive disorder, ${ }^{2} D H E A S$

Dehydroepiandrosterone and its sulfate, ${ }^{3} / G F 1$ Insulin-like growth factor 1 , ${ }^{4}$ HbAic Glycated hemoglobin

correlated with GAF scores $(\mathrm{R}=0.473, P<0.001)$ (Fig. 1b). Serum cortisol levels, serum DHEAS levels, serum IGF1 levels, and serum testosterone levels were not significantly correlated with HAM-D scores. Stepwise multiple regression analysis indicated that as serum estradiol levels decreased, HAM-D scores increased (Table 3).

According to Pearson's correlation analysis, patients' estradiol levels were positively correlated with DHEAS levels $(\mathrm{R}=0.332, P=0.014)$ and with testosterone levels $(\mathrm{R}=0.423, P=0.001)$; IGF1 levels were positively correlated with DHEAS levels $(\mathrm{R}=0.451, P=0.001)$. No significant differences were found between other hormones in patients. In controls, estradiol levels were positively correlated with testosterone levels $(\mathrm{R}=0.416, P=0.01)$, but no significant differences were found between other hormones, including estradiol and IGF1 levels. Stepwise multiple regression analysis showed no correlation between IGF1 and DHEAS, whereas estradiol was correlated with DHEAS and testosterone (Table 4).

\section{Discussion}

\section{Serum estradiol levels in male patients with MDD}

In the current study, serum estradiol levels were negatively correlated with the severity of depression in male patients. In a previous study among healthy men, plasma estradiol levels were positively correlated with serotonin $2 \mathrm{~A}$ receptor (5-HT 2AR) binding in the cerebral cortex [22], which is consistent with the results of our study. However, no previous study has shown a correlation between estradiol and severity of MDD in males, as in our study.

Several studies have shown that estradiol is involved with the pathogenesis of male MDD, and we also found that serum estradiol levels in male patients were lower 

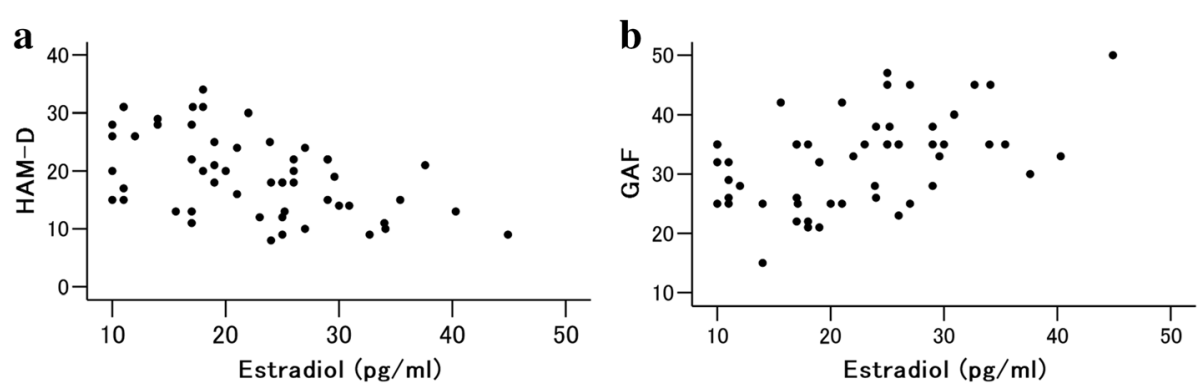

Fig. 1 Scatterplot of serum estradiol versus HAM-D (a) and serum estradiol versus GAF scores (b) in male patients with MDD. Serum estradiol showed significant negative correlation with HAM-D scores $(P=0.0000940)(\mathbf{a})$ and significant positive correlation with GAF scores $(P=0.000299)(\mathbf{b})$

than in male controls. Through estradiol supplementation, depression-like behaviors induced by gonadectomy were improved in male rats [23]. In a different study of male mice, activation of estrogen receptor $\beta$ in the striatum increased serotonin levels and showed antidepressant effects [24]. Furthermore, the administration of estradiol in male rats increased the binding site densities of 5-HT 2AR and serotonin transporter in the dorsal raphe nucleus [25-27]. In a clinical study, Eskelinen et al. [28] compared serum estradiol levels in 74 elderly men with depressive disorders and 367 controls; consistent with our results, serum estradiol levels were lower in depressed patients than in controls. However, several studies of male patients with MDD have found no significant differences in serum estradiol levels between patients and controls [29-31]. It should be noted that all of those studies had small sample sizes, with the maximum including 22 male patients with MDD. Our study included 54 patients, a larger sample size than those past studies, which may be the reason for the difference in results.

\section{IGF1, DHEAS, cortisol:DHEAS ratio, cortisol, and testosterone in male patients with MDD}

The patients in the current study had higher serum IGF1 levels and lower serum DHEAS levels than the controls. The cortisol:DHEAS ratio was higher in patients, but serum cortisol and testosterone levels were not different.

In a meta-analysis for patients with MDD and bipolar disorder [16], as well as a meta-analysis of patients with MDD [11], serum IGF1 levels were higher and serum DHEAS levels were lower in patients than in controls.
Therefore, our study supports these previous results analyzing both men and women, and we hypothesize that there is an association between estradiol, IGF1, and DHEAS in male MDD. Several non-MDD studies have shown an association of these hormones with other conditions. A study of men with congenital aromatase deficiency indicated that estradiol regulates the production of IGF1 [18]. In a study including 12,300 men in the general population, estradiol was positively correlated with DHEAS [15]. Therefore, it is possible that estradiol is co-regulated with IGF1 and DHEAS. Furthermore, our study showed a positive correlation between estradiol and DHEAS in male patients with MDD but not in controls. To determine whether the relationships between these hormones, or differences in the regulatory function of MDD and controls, are related to the pathology of male MDD, further studies are needed.

Activation of the HPA axis is widely recognized as one of the factors involved in the pathogenesis of MDD [7-10, 12], and an increased cortisol:DHEAS ratio in MDD has been demonstrated [12]. Our study also showed an increase in the cortisol:DHEAS ratio, although no increase was observed in serum cortisol levels. HPA axis function can also be decreased in depressed patients [32, 33]. As described above, results linking the HPA axis with MDD are inconsistent. However, some studies have shown that the HPA axis function may be reduced using antidepressants $[8,34$, 35 ] and that this may be different for melancholic and atypical depression [36]. Our study allowed the use of antidepressants and did not distinguish between the subtypes of MDD; therefore, further research is needed to consider these factors.

Table 3 Stepwise multiple regression analysis of the relationship between HAM-D scores and dependent variables

\begin{tabular}{lccccc}
\hline Independent Variables & Adjusted $\boldsymbol{R}^{\mathbf{2}}$ & Constant & $\boldsymbol{F}$ & $\boldsymbol{\beta}$ & SE \\
\hline Total mode & 0.242 & 28.827 & 17.916 & & $\boldsymbol{P}$ \\
Estradiol & & & -0.424 & 0.000094 \\
\hline
\end{tabular}


Table 4 Stepwise multiple regression analysis of the relationship between estradiol levels and dependent variables in patients

\begin{tabular}{lccccc}
\hline Independent Variables & Adjusted $\boldsymbol{R}^{\mathbf{2}}$ & Constant & $\boldsymbol{F}$ & $\boldsymbol{\beta}$ & SE \\
\hline Total mode & 0.289 & 3.880 & 11.786 & & $\boldsymbol{P}$ \\
Testosterone & & & 2.388 & 0.610 \\
DHEAS & & & 0.029 & 0.0000062 \\
\hline
\end{tabular}

Regarding testosterone, several studies have shown a relationship between a decrease in testosterone and depression, but the results are inconsistent [2, 37-39]. In a recent study using male rats, antidepressant-like effects of testosterone were shown to be partly mediated by its conversion to estradiol [23]. As our study demonstrated the relationship between estradiol and testosterone, further analysis involving estradiol and testosterone in male MDD is warranted.

\section{Limitations of this study}

The current study had several limitations. First, our sample size was small, so detectability may have been limited. Additionally, the use of antidepressant medication may have been a confounding factor. Second, we did not classify the subtypes of depression. Third, we did not take into account psychosocial factors (e.g., employment status), which could be confounding factors for cortisol levels.

\section{Conclusion}

Estradiol may affect the pathogenesis and severity of MDD in men and other hormones, such as those in the HPA and HPS axes, may also be involved in male MDD. Furthermore, the correlation between estradiol and DHEAS may affect the pathology of MDD in men. Further research is needed to examine the relationship between estradiol and these other hormones in male MDD.

\section{Abbreviations \\ BMI: Body mass index; DHEAS: Dehydroepiandrosterone sulfate; GAF: Global Assessment of Functioning; HAM-D: Hamilton Depression Rating Scale; HPA: Hypothalamic-pituitary-adrenal; HPG: Hormones of the hypothalamic- pituitary-gonadal; HPS: Hypothalamic-pituitary-somatotropic; IGF1: Insulin- like growth factor 1; MDD: Major depressive disorder}

\section{Acknowledgements}

We thank Jeremy Allen, PhD, from Edanz Group (https://en-author-services. edanz.com/ac) for editing a draft of this manuscript.

\section{Authors' contributions}

HA, YS, MT, NT, and TS were involved in the concept and design of the study. HA, YS, MT, and NT contributed to acquisition of the data. HA and YS were the principal investigators and performed the analysis and drafted the first manuscript. HA, YS, MT, NT, and TS contributed to writing the manuscript and approved the final version.

\section{Funding}

The study was funded by Grants-in-Aid for Scientific Research (KAKENHI) from the Japan Society for the Promotion of Research (JSPS, \#17 K10268) to YS, and a Grant-in-Aid for Scientific Research (KAKENHI) from JSPS (\#16 K19755 and \#19 K17085) to NT. The funders had no role in the study design, data collection and analysis, decision to publish, or preparation of the manuscript. The other authors have no other sources of funding.

\section{Availability of data and materials}

All data generated or analyzed during this study are included in this published article.

\section{Ethics approval and consent to participate}

This study was approved by the Genetics Ethics Committee of Niigata University Graduate School of Medical and Dental Sciences and conforms to the provisions of the Declaration of Helsinki. All participants provided written informed consent before participating in the study. Informed consent was obtained from parents and/or legal guardian of patients with MDD if the patient's capacity to grant consent was compromised.

\section{Consent for publication}

Not applicable.

\section{Competing interests}

The authors declare that they have no competing interests.

Received: 30 November 2020 Accepted: 10 February 2021

Published online: 17 March 2021

\section{References}

1. McHenry J, Carrier N, Hull E, Kabbaj M. Sex differences in anxiety and depression: role of testosterone. Front Neuroendocrinol. 2014;35(1):42-57.

2. Fischer S, Ehlert U, Amiel CR. Hormones of the hypothalamic-pituitarygonadal (HPG) axis in male depressive disorders-a systematic review and meta-analysis. Front Neuroendocrinol. 2019. https://doi.org/10.1016/j.yfrne.2 019.100792.

3. Komesaroff $P$, Fullerton M, Esler MD, Jennings $G$, Sudhir K. Oestrogen supplementation attenuates responses to psychological stress in elderly men rendered hypogonadal after treatment for prostate cancer. Clin Endocrinol (Oxf). 2002;56(6):745-53.

4. Fisher AD, Castellini G, Bandini E, Casale H, Fanni E, Benni L, et al. Cross-sex hormonal treatment and body uneasiness in individuals with gender dysphoria. J Sex Med. 2014;11(3):709-19.

5. Colizzi M, Costa R, Todarello O. Transsexual patients' psychiatric comorbidity and positive effect of cross-sex hormonal treatment on mental health: results from a longitudinal study. Psychoneuroendocrinology. 2014;39:65-73.

6. Achille C, Taggart T, Eaton NR, Osipoff J, Tafuri K, Lane A, et al. Longitudinal impact of gender-affirming endocrine intervention on the mental health and well-being of transgender youths: preliminary results. Int J Pediatr Endocrinol. 2020. https://doi.org/10.1186/s13633-020-00078-2.

7. Holsboer $F$. The corticosteroid receptor hypothesis of depression. Neuropsychopharmacology. 2000;23:477-501.

8. McKay MS, Zakzanis KK. The impact of treatment on HPA Axis activity in unipolar major depression. J Psychiatr Res. 2010;44(3):183-92.

9. Belvederi Murri M, Pariante C, Mondelli V, Masotti M, Atti AR, Mellacqua Z, et al. HPA axis and aging in depression: systematic review and metaanalysis. Psychoneuroendocrinology. 2014;41:46-62.

10. Rothe N, Steffen J, Penz M, Kirschbaum C, Walther A. Examination of peripheral basal and reactive cortisol levels in major depressive disorder and the burnout syndrome: a systematic review. Neurosci Biobehav Rev. 2020; 114:232-70.

11. Zhu G, Yin Y, Xiao CL, Mao RJ, Shi BH, Jie Y, et al. Serum DHEAS levels are associated with the development of depression. Psychiatry Res. 2015;229(12):447-53.

12. Young AH, Gallagher P, Porter RJ. Elevation of the cortisoldehydroepiandrosterone ratio in drug-free depressed patients. Am J Psychiatry. 2002;159(7):1237-9.

13. Oyola MG, Handa RJ. Hypothalamic-pituitary-adrenal and hypothalamicpituitary-gonadal axes: sex differences in regulation of stress responsivity. Stress. 2017;20(5):476-94. 
14. Acevedo-Rodriguez A, Kauffman AS, Cherrington BD, Borges CS, Roepke TA, Laconi M. Emerging insights into hypothalamic-pituitary-gonadal axis regulation and interaction with stress signalling. J Neuroendocrinol. 2018. https://doi.org/10.1111/jne.12590.

15. Watts EL, Appleby PN, Albanes D, Black A, Chan JM, Chen C, et al. Circulating sex hormones in relation to anthropometric, sociodemographic and behavioural factors in an international dataset of 12,300 men. PLoS One. 2017. https://doi.org/10.1371/journal.pone.0187741.

16. Tu KY, Wu MK, Chen YW, Lin PY, Wang HY, Wu CK, et al. Significantly higher peripheral insulin-like growth Factor-1 levels in patients with major depressive disorder or bipolar disorder than in healthy controls: a metaanalysis and review under guideline of PRISMA. Medicine (Baltimore). 2016. https://doi.org/10.1097/MD.0000000000002411.

17. Bianchi VE, Locatelli V, Rizzi L. Neurotrophic and Neuroregenerative effects of GH/IGF1. Int J Mol Sci. 2017. https://doi.org/10.3390/ijms18112441.

18. Russell N, Grossmann M. Mechanisms in endocrinology: estradiol as a male hormone. Eur J Endocrinol. 2019:181(1):23-43.

19. Netherton C, Goodyer I, Tamplin A, Herbert J. Salivary cortisol and dehydroepiandrosterone in relation to puberty and gender. Psychoneuroendocrinology. 2004;29(2):125-40.

20. Zhu H, Xu Y, Gong F, Shan G, Yang H, Xu K. Reference ranges for serum insulin-like growth factor I (IGF-I) in healthy Chinese adults. PLoS One. 2017. https://doi.org/10.1371/journal.pone.0185561.

21. Aas $\mid H$. Guidelines for rating global assessment of functioning (GAF). Ann Gen Psychiatry. 2011. https://doi.org/10.1186/1744-859X-10-2.

22. Frokjaer VG, Erritzoe D, Juul A, Nielsen FA, Holst K, Svarer C, et al. Endogenous plasma estradiol in healthy men is positively correlated with cerebral cortical serotonin 2A receptor binding. Psychoneuroendocrinology. 2010;35(9):1311-20.

23. Carrier N, Saland SK, Duclot F, He H, Mercer R, Kabbaj M. The anxiolytic and antidepressant-like effects of testosterone and estrogen in gonadectomized male rats. Biol Psychiatry. 2015;78(4):259-69.

24. Hughes ZA, Liu F, Platt BJ, Pulicicchio CM, Zhang G, Schechter LE, et al. WAY-200070, a selective agonist of estrogen receptor beta as a potential novel anxiolytic / antidepressant agent. Neuropharmacology. 2008;54(7): $1136-42$.

25. Sumner BE, Fink G. Testosterone as well as estrogen increases serotonin2A receptor $m R N A$ and binding site densities in the male rat brain. Brain Res Mol Brain Res. 1998;59(2):205-14.

26. Fink G, Sumner B, Rosie R, Wilson H, McQueen J. Androgen actions on central serotonin neurotransmission: relevance for mood, mental state and memory. Behav Brain Res. 1999;105(1):53-68.

27. McQueen JK, Wilson H, Sumner BE, Fink G. Serotonin transporter (SERT) mRNA and binding site densities in male rat brain affected by sex steroids. Brain Res Mol Brain Res. 1999;63(2):241-7.

28. Eskelinen SI, Vahlberg TJ, Isoaho RE, Kivelä SL, Irjala KM. Associations of sex hormone concentrations with health and life satisfaction in elderly men. Endocr Pract. 2007;13(7):743-9.

29. Rupprecht R, Rupprecht C, Rupprecht M, Noder M, Schwarz W. Different reactivity of the hypothalamo-pituitary-gonadal-axis in depression and normal controls. Pharmacopsychiatry. 1988;21(6):438-9.

30. Rubin RT, O'Toole SM, Rhodes ME, Sekula LK, Czambel RK. Hypothalamopituitary-adrenal cortical responses to low-dose physostigmine and arginine vasopressin administration: sex differences between major depressives and matched control subjects. Psychiatry Res. 1999;89(1):1-20.

31. Findikli E, Kurutas EB, Camkurt MA, Karaaslan MF, Izci F, Fındıkı HA, et al. Increased serum G protein-coupled estrogen receptor 1 levels and its diagnostic value in drug Naïve patients with major depressive disorder. Clin Psychopharmacol Neurosci. 2017;15(4):337-42.

32. Oldehinkel AJ, d B V , Flentge F, Bouhuys AL, ter Horst GJ, Ormel J. Urinary free cortisol excretion in elderly persons with minor and major depression. Psychiatry Res. 2001;104:39-47.

33. Bremmer MA, Deeg DJ, Beekman AT, Penninx BW, Lips P, Hoogendijk WJ. Major depression in late life is associated with both hypo- and hypercortisolemia. Biol Psychiatry. 2007;62(5):479-86.

34. Nickel T, Sonntag A, Schill J, Zobel AW, Ackl N, Brunnauer A, et al. Clinical and neurobiological effects of tianeptine and paroxetine in major depression. J Clin Psychopharmacol. 2003;23(2):155-68.

35. Schule C, Baghai TC, Eser D, Schwarz M, Bondy B, Rupprecht R. Effects of mirtazapine on dehydroepiandrosterone-sulfate and cortisol plasma concentrations in depressed patients. J Psychiatr Res. 2009;43:538-45.
36. Juruena MF, Bocharova M, Agustini B, Young AH. Atypical depression and non-atypical depression: is HPA Axis function a biomarker? A systematic review. J Affect Disord. 2018;233:45-67.

37. Johnson JM, Nachtigall LB, Stern TA. The effect of testosterone levels on mood in men: a review. Psychosomatics. 2013;54(6):509-14.

38. Duke SA, Balzer BW, Steinbeck KS. Testosterone and its effects on human male adolescent mood and behavior: a systematic review. J Adolesc Health. 2014;55(3):315-22

39. See CK, Turnbull D, Ritson F, Martin S, Tully P, Wittert G. Association of endogenous testosterone concentration with depression in men: a systematic review protocol. JBI Database System Rev Implement Rep. 2019; 17(9):1894-900

\section{Publisher's Note}

Springer Nature remains neutral with regard to jurisdictional claims in published maps and institutional affiliations.
Ready to submit your research? Choose BMC and benefit from:

- fast, convenient online submission

- thorough peer review by experienced researchers in your field

- rapid publication on acceptance

- support for research data, including large and complex data types

- gold Open Access which fosters wider collaboration and increased citations

- maximum visibility for your research: over $100 \mathrm{M}$ website views per year

At BMC, research is always in progress.

Learn more biomedcentral.com/submissions 